\title{
PHAEOACREMONIUM VRSTE U VINOVOJ LOZI SA SIMPTOMIMA ESKE I PETRIJEVE BOLESTI
}

\author{
PHAEOACREMONIUM SPECIES IN GRAPEVINES WITH ESCA \\ AND PETRI DISEASE SYMPTOMS
}

\author{
D. Ivić, Zdravka Sever, Petra Pilipović, Ana Marija Čajkulić, \\ B. Cvjetković
}

\section{SAŽETAK}

Gljive iz roda Phaeoacremonium ubrajaju se među uzročnike eske i eski sličnih bolesti vinove loze. Od 2009. do 2014., u šest vinograda (Kutjevo, Ilok, Nadin, Buje i Vukomeričke Gorice) sakupljeno je 16 uzoraka trsova sa simptomima Petrijeve bolesti (mladi vinograd u Nadinu) ili eske (ostali vinogradi). U 13 uzoraka nađene su vrste iz roda Phaeoacremonium, od toga u pet uzoraka u savršenom stadiju (periteciji), a u ostalih osam uzoraka u kondijskom stadiju. Analizom izolata na temelju morfologije i analizom sekvenci ITS1-5.8S-ITS2 ribosomske DNA utvrđeno je da izolati pripadaju vrstama Phaeoacremonium mortoniae (11 izolata), P. aleophilum (jedan izolat) i P. rubrigenum (jedan izolat). Za pet izolata koji su dobiveni iz peritecija nađenih na uzorcima vinove loze utvrđeno je da pripadaju vrstama Togninia fraxinopennsylvanica (P. mortoniae), T. minima (P. aleophilum) i T. rubrigena $(P$. rubrigenum). Rezultati predstavljaju prvi nalaz savršenih stadija Phaeoacremonium vrsta na vinovoj lozi u Hrvatskoj i upućuju na mogućnost da se spomenuti patogeni, uzročnici eske i eski sličnih bolesti, mogu razmnožavati konidijama i askosporama.

Ključne riječi: Phaeoacremonium, Togninia, eska, Petrijeva bolest

\begin{abstract}
Fungi from the genus Phaeoacremonium are known to be among the causal agents of grapevine esca and esca-like diseases. From 2009 to 2014, 16 symptomatic samples of grapevine with esca or Petri disease symptoms were collected in Nadin (Petri disease symptoms), Kutjevo, Ilok, Buje and Vukomeričke Gorice (esca symptoms). Phaeoacremonium species were found in 13 samples. Perithecial stage (Togninia) was found in five samples, while only conidial stage was recorded in the other eight samples. Morphological
\end{abstract}


D. Ivić i sur.: Phaeoacremonium vrste u vinovoj lozi sa simptomima eske i Petrijeve bolesti

analysis and phylogenetic analysis of ITS1-5.8S-ITS2 ribosomal DNA sequences showed that 11 isolates can be identified as Phaeoacremonium mortoniae, one isolate as $P$. aleophilum and one isolate as $P$. rubrigenum. Five isolates derived from perithecia found on grapevine wood were confirmed as Togninia fraxinopennsylvanica ( $P$. mortoniae), T. minima ( $P$. aleophilum) and T. rubrigena ( $P$. rubrigenum). This is the first record of Phaeoacremonium teleomorphs on grapevine in Croatia, which indicates that these causal agents of esca and esca-like diseases can reproduce both with conidia and ascospores.

Keywords: Phaeoacremonium, Togninia, esca, Petri disease

\section{UVOD}

Eska je jedna od najranije opisanih bolesti vinove loze, no njena etiologija nije bila razjašnjena sve do početka 21. stoljeća (Surico i sur., 2006.; Mugnai i sur., 1999.). Iako se pojam „eska“ još uvijek često koristi za sve tipove bolesti drva vinove loze, sve se više prihvaća razdvajanje tog naziva na „pravu esku“, „mladenačku esku“ i Petrijevu bolest vinove loze (Surico i sur., 2006.). Uz sve te tipove bolesti još uvijek se vežu određene nepoznanice ili nesuglasice (Hofstetter i sur., 2012.; Surico, 2009.), no eska i eski slične bolesti raširene su u čitavom svijetu i uzrokuju velike ekonomske gubitke u svjetskom vinogradarstvu (Bertsch i sur., 2013.).

Iako je etiologija bolesti drva vinove loze kompleksna (Bertsch i sur., 2013.; Surico i sur., 2006.), glavnim uzročnicima „prave eske“ i Petrijeve bolesti smatraju se gljive Phaeomoniella chlamydospora (W. Gams, Crous, M.J. Wingf $\&$ L. Mugnai) Crous \& W. Gams i vrste iz roda Phaeoacremonium (Bertsch i sur., 2013.; Surico i sur., 2006.). Gljive iz roda Phaeoacremonium izolirane su iz brojnih drvenastih biljaka domaćina, no najčešće se spominju upravo u kontekstu eske i eski sličnih bolesti vinove loze (Mostert i sur., 2006.). Veći broj do sada opisanih Phaeoacremonium vrsta pokazao se patogenim za vinovu lozu (Aroca i Raposo, 2009.; Surico i sur., 2006.; Sparapano i sur., 2001.). Phaeoacremonium vrste na vinovoj lozi uzrokuju tamnjenje drva i provodnog staničja, začepljenje ksilema, nekroze na listovima i pojavu tamnih točaka na bobicama (Bertsch i sur., 2013.; Aroca i Raposo, 2009.; Bruno i sur., 2006.; Gubler i sur., 2004.). Osim na vinovoj lozi, različite Phaeoacremonium vrste mogu biti patogene i na drugim drvenastim biljkama domaćinima (Carlucci i sur., 2015.; Mostert i sur., 2006.). Savršeni stadiji Phaeoacremonium vrsta, u slučajevima kada su nađeni, svrstani su u rod Togninia (Mostert i sur., 2006).. 
D. Ivić i sur.: Phaeoacremonium vrste u vinovoj lozi sa simptomima eske i Petrijeve bolesti

Eska vinove loze raširena je u čitavoj Hrvatskoj (Ivić i sur., 2015.; Cvjetković, 2010.), u intenzitetu koji je vrlo različit od vinograda do vinograda (Ivić i sur., 2015.). Cilj rada bio je utvrditi i identificirati Phaeoacremonium vrste iz uzoraka vinove loze sa simptomima eske ili Petrijeve bolesti iz različitih područja Hrvatske.

\section{MATERIJALI I METODE}

Uzorci drva vinove loze sakupljeni su od 2009. do 2014. godine u nekoliko vinograda gdje je manji ili veći broj čokota pokazivao tipične simptome eske ili Petrijeve bolesti. Uzorci su sakupljeni u vinogradu u okolici Iloka (simptomi eske), u dva vinograda u okolici Kutjeva (simptomi eske), u vinogradu u okolici Buja (simptomi eske), u vinogradu u Vukomeričkim Goricama (simptomi eske) te u mladom dvogodišnjem vinogradu u okolici Benkovca (simptomi Petrijeve bolesti). Sorte s kojih su uzeti uzroci bile su Chardonnay (Ilok), Graševina (Kutjevo i Vukomeričke Gorice), Rajnski rizling (Kutjevo), Teran (Buje) i Debit (Benkovac).

Odabrani simptomatični trsovi prerezani su pilom pri vrhu debla kako bi se vidjeli unutarnji simptomi u drvu. Nakon toga, sa svakog trsa uzet je dio glavnog debla dužine 20-tak $\mathrm{cm}$ i dopremljen u laboratorij. Ukupno je sakupljeno 16 uzoraka, od toga osam u Kutjevu, po tri u Iloku i u Nadinu te po jedan iz Buja i Vukomeričkih Gorica (Tablica 1.). Dijelovi debla prerezani su na dva dijela. Jedan dio je ispran pod mlazom tekuće vode, površinski steriliziran jednu minutu u $70 \%$-tnom etanolu, kratko ispran sterilnom vodom, osušen i ostavljen u vlažnoj komori na sobnoj temperaturi. Drugom dijelu oguljena je kora te je uzdužno i poprečno razrezan na manje dijelove. Razrezani dijelovi su površinski sterilizirani u $1 \%$-tnoj otopini natrijevog hipoklorita, isprani u sterilnoj vodi, osušeni i stavljeni na inkubaciju u vlažnu komoru na temperaturi od $22{ }^{\circ} \mathrm{C}$. Nakon inkubacije od 7-15 dana, na svim dijelovima drva analiziran je razvoj gljiva pod stereomikroskopom. Analizirana je prisutnost plodnih tijela i micelija. Po potrebi, razvijeni micelij ili plodna tijela pregledani su mikroskopski kako bi se utvrdila eventualna prisutnost gljiva iz roda Phaeoacremonium. U slučajevima kada je micelij Phaeoacremonium vrsta nađen, sterilnom iglom je inokuliran na krumpir-dekstrozni agar (KDA). U slučajevima kada su nađeni periteciji koji bi prema morfologiji mogli pripadati rodu Togninia, sterilnom su iglom pojedinačno preneseni na KDA. 
D. Ivić i sur.: Phaeoacremonium vrste u vinovoj lozi sa simptomima eske i Petrijeve bolesti

Tablica 1. Broj i porijeklo uzoraka vinove loze sa simptomima eske ili Petrijeve bolesti u kojima su utvrđene gljive iz roda Phaeoacremonium u savršenom ili nesavršenom stadiju.

Table 1 Number and origin of samples of grapevine with esca of Petri disease symptoms in which Phaeoacremonium species were found in perfect or in imperfect state.

\begin{tabular}{|c|c|c|c|c|}
\hline $\begin{array}{c}\text { Porijeklo } \\
\text { uzorka } \\
\begin{array}{c}\text { Sample } \\
\text { origin }\end{array}\end{array}$ & $\begin{array}{c}\text { Broj } \\
\text { uzoraka } \\
\text { Nomples } \\
\text { samples }\end{array}$ & $\begin{array}{c}\text { Broj uzoraka s nađenim } \\
\text { Phaeoacremonium } \\
\text { vrstama } \\
\text { No. of samples with } \\
\text { Phaeoacremonium } \\
\text { species found }\end{array}$ & $\begin{array}{c}\text { Broj uzoraka s } \\
\text { nađenim teleomorfom } \\
\text { (Togninia) } \\
\text { No. of samples with } \\
\text { teleomorph } \\
\text { (Togninia) found }\end{array}$ & $\begin{array}{c}\text { Broj uzoraka s } \\
\text { nađenim } \\
\text { anamorfom } \\
\text { No. of samples } \\
\text { with anamorph } \\
\text { found }\end{array}$ \\
\hline Kutjevo & 8 & 6 & 4 & 2 \\
\hline Ilok & 3 & 2 & - & 2 \\
\hline Nadin & 3 & 3 & - & 3 \\
\hline Buje & 1 & 1 & - & - \\
\hline $\begin{array}{c}\text { Vukomeričke } \\
\text { Gorice }\end{array}$ & 1 & 1 & 1 & 1 \\
\hline
\end{tabular}

Nakon inkubacije od 14-30 dana, kulture na KDA su analizirane makroskopski i mikroskopski. Promatrani su izgled, rast i boja kolonije, hife, konidiofori, fijalide i konidije. Izolati koji su prema morfologiji odgovarali opisu roda Phaeoacremonium (Mostert i sur., 2006.) precijepljeni su s ruba kolonije u čistu kulturu i molekularno analizirani. Ukupno je analizirano 13 izolata.

Izolati su uzgajani 10 dana na KDA s celofanom, nakon čega je micelij sastrugan i usitnjen u tekućem dušiku. Ukupna DNA iz micelija ekstrahirana je kompletom DNEasy Plant Mini Kit ${ }^{\circledR}$ (Quiagen Inc., SAD) prema uputama proizvođača. Količina i kakvoća ekstrahirane DNA provjerena je na spektrofotometru. Ekstrakti DNA korišteni su u PCR reakciji s parom početnica ITS1/ITS4 (White i sur., 1990), u reakcijskoj smjesi i prema parametrima umnožavanja kako opisuju Mostert i sur. (2006). Produkti reakcije pročišćeni su korištenjem kompleta GenElute PCR Clean-Up Kitß (Sigma, SAD) i sekvencirani. Sekvence su uređene u programu Sequencher ${ }^{\circledR}$ (Gene Codes Corporation, SAD) i korištene u UPGMA filogenetskoj analizi s referentnim sekvencama iz GenBank ${ }^{\circledR}$ baze podataka. Sekvence Phaeoacremonium mortoniae CBS 101585 (AF295328.1), P. aleophilum CBS 246.91 (AY199934.1) i P. rubrigenum CBS 566.97 (AF197979) korištene su kao referentne sekvence. Filogenetske analize provedene su u programu MEGA 5.05 (Tamura i sur., 2011.). 
D. Ivić i sur.: Phaeoacremonium vrste u vinovoj lozi sa simptomima eske i Petrijeve bolesti

\section{REZULTATI}

Na presjeku svih 13 čokota sa simptomima eske bili su vidljivi tipični znakovi te bolesti unutar drva. Svi čokoti bili su iznutra više ili manje zahvaćeni s truleži drva. Na presjeku tri čokota sa simptomima Petrijeve bolesti bili su vidljivi potamnjeli provodni snopovi, no bez truleži drva. Od ukupno 16 uzoraka, gljive iz roda Phaeoacremonium izolirane su iz njih 13 (Tablica 1.). U tri uzorka (jedan iz Iloka i dva iz Kutjeva) gljive iz roda Phaeoacremonium nisu nađene.

Kulture sakupljenih izolata na KDA bile su bjeličaste, žuto-smeđe ili sive boje. Konidiofori su se stvarali na zračnom miceliju, bili su razgranati ili nerazgranati, s vršnim konidiogenim stanicama (fijalidama) na kojima su nastajale konidije u okruglim nakupinama. Konidije su se stvarale kod svih 16 izolata i bile su jednostanične, bezbojne i ovalno-izdužene ili bubrežaste. Morfologija svih izolata odgovarala je opisu roda Phaeoacremonium (Mostert i sur., 2006.). Izolati su na temelju morfologije determinirani kao P. mortoniae, $P$. aleophilum i $P$. rubrigenum.

Periteciji nađeni na uzorcima iz Kutjeva i Vukomeričkih Gorica i inokulirani na KDA (izolati PDV1, DV1, PERI, DV3 i PER IT) dali su kolonije bjeličaste do žuto-smeđe, sa svim prethodno opisanim morfološkim obilježjima karakterističnima za rod Phaeoacremonium.

UPGMA filogenetsko stablo na osnovi sekvenci ITS1-5.8S-ITS2 ribosomske DNA referentnih izolata i izolata iz istraživanja pokazalo je jasno odvajanje tri grupe i grupiranje izolata s referentnim izolatima $P$. mortoniae, $P$. aleophilum i $P$. rubrigenum (Slika 2.). Filogenetska analiza potvrdila je identifikaciju izolata. Izolati PCNSA, PCN1, PDV1, PCNL, DV1, PERI, PCH5, PCH L, PCH1, PCH6 i PAL6 identificirani su kao P. mortoniae (Togninia fraxinopennsylvanica), izolat DV3 kao $P$. aleophilum (Togninia minima), a izolat PER IT kao P. rubrigenum (Togninia rubrigena).

Morfološka i molekularna identifikacija izolata potvrdila je da periteciji nađeni na uzorcima vinove loze iz Kutjeva i iz Vukomeričkih Gorica pripadaju vrstama $T$. fraxinopennsylvanica ( $P$. mortoniae), T. minima $(P$. aleophilum) i T. rubrigena ( $P$. rubrigenum). Na uzrocima iz Kutjeva utvrđeni su periteciji T. fraxinopennsylvanica (izolati PDV1, DV1 i PERI) i periteciji T. minima (izolat DV3), dok su u uzorku iz Vukomeričkih Gorica utvrđeni periteciji T. rubrigena (izolat PER IT). 
D. Ivić i sur.: Phaeoacremonium vrste u vinovoj lozi sa simptomima eske i Petrijeve bolesti

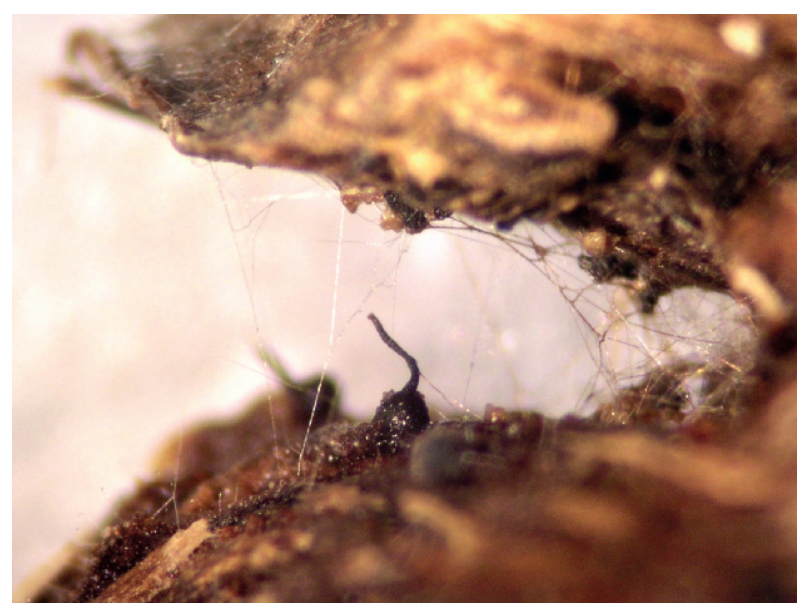

Slika 1. Peritecij Togninia fraxinopennsylvanica unutar drva vinove loze.

Picture 1 Togninia fraxinopennsylvanica perithecium in grapevine wood.

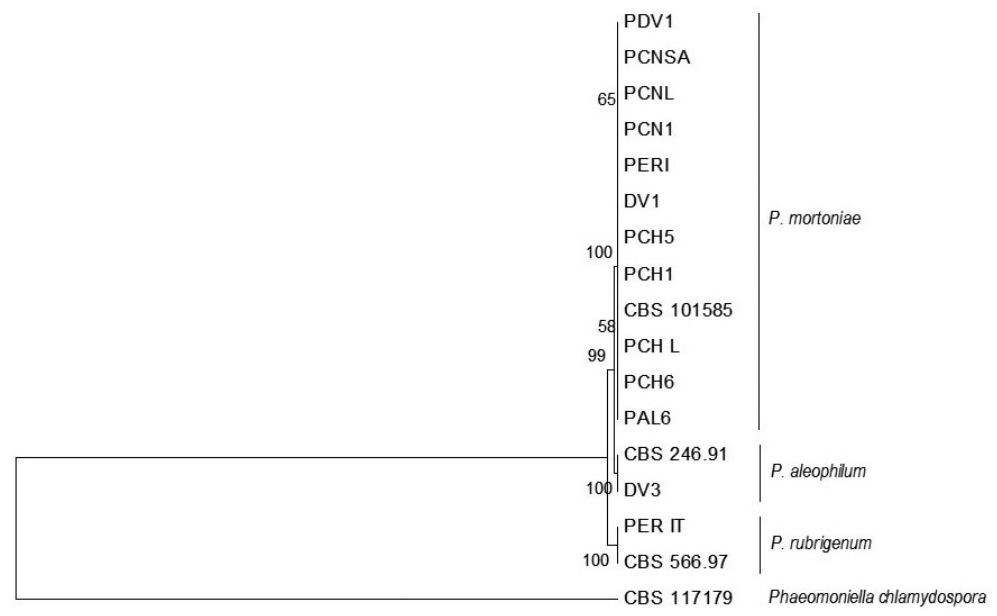

Slika 2. UPGMA filogenetsko stablo na temelju sekvenci ITS1-5.8S-ITS2 ribosomske

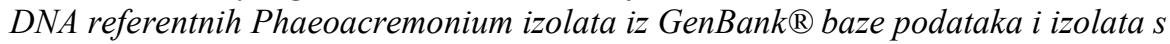
vinove loze iz istraživanja. Vrijednosti na ograncima temelje se na 500 ponavljanja.

Picture 2 UPGMA phylogenetic tree derived from sequences of ITS1-5.8S-ITS2 ribosomal DNA of reference Phaeoacremonium isolates deposited in GenBank $\odot$ and isolates from grapevine analysed in the study. Bootstrap interior-branch values are based on 500 replicates. 
D. Ivić i sur.: Phaeoacremonium vrste u vinovoj lozi sa simptomima eske i Petrijeve bolesti

\section{RASPRAVA}

Unutar roda Phaeacremonium trenutno je opisano gotovo 50 vrsta (Gramaje i sur., 2015.), među kojima je veći broj nađen na vinovoj lozi i smatra se uzročnikom eske i eski sličnih bolesti (Gramaje i sur., 2015.; Mostert i sur., 2006.; Surico i sur., 2006.). U ovom istraživanju determinirane su vrste $P$. mortoniae, $P$. aleophilum i $P$. rubrigenum, među kojima je dominantna bila P. mortoniae (T. fraxinopennsylvanica). Iste tri Phaeoacremonium vrste utvrdili su Essakhi i sur. (2008.) u simptomatičnim uzorcima vinove loze iz Hrvatske.

P. aleophilum navodi se kao najčešća Phaeoacremonium vrsta na vinovoj lozi u svijetu (Mostert i sur., 2006.; Mugnai i sur., 1999.) i uz vrstu $P$. chlamydospora smatra se jednim od glavnih uzročnika Petrijeve bolesti i svih tipova eske (Gramaje i sur., 2015.; Bertsch i sur., 2013.). Vrste P. mortoniae i $P$. rubrigenum zabilježene su na vinovoj lozi i navode se među uročnicima eske i eski sličnih bolesti, no rjeđe nego vrsta $P$. aleophilum (Essakhi i sur., 2008.; Mostert i sur., 2006.; Eskalen i sur., 2005.).

Periteciji T. minima, teleomorfa vrste $P$. aleophilum, nađeni su $\mathrm{u}$ pukotinama na kori $\mathrm{i}$ na ranama od rezidbe $\mathrm{u}$ vinogradima $\mathrm{u}$ Kaliforniji (Rooney-Latham i sur., 2005.). Slično su utvrdili Eskalen i sur. (2005.) za vrstu $T$. fraxinopennsylvanica, teleomorfa vrste $P$. mortoniae. Na temelju svojih opažanja, Rooney-Latham i sur. (2005.) iznose pretpostavku da se $P$. aleophilum (T. minima) unutar vinograda širi isključivo askosporama. Eskalen i sur. (2005.) takvu su pretpostavku potvrdili za vrstu $P$. mortoniae (T. fraxinopennsylvanica), čije su askospore uhvatili u vinogradu nakon kiša tijekom vegetacijske sezone. Slično kao u spomenutim istraživanjima iz Kalifornije, u ovom istraživanju je također utvrđena prisutnost peritecija T. minima i $T$. fraxinopennsylvanica na površini i unutar drva vinove loze sa simptomima eske. Nalaz peritecija te dvije vrste upućuje da se ta dva uzročnika eske i eski sličnih bolesti u Hrvatskoj također razmnožavaju spolno i vjerojatno šire askosporama. Razdoblje oslobađanja njihovih askospora nije poznato, no moguće je pretpostaviti da se oslobađaju nakon kiša i šire na veće udaljenosti unutar i izvan vinograda. Nalaz nesavršenog stadija (Phaeoacremonium) i savršenog stadija (Togninia) na simptomatičnim biljkama u ovom istraživanju pokazuje da se na zaraženom čokotu vinove loze mogu stvarati dva tipa inokula kojima se zaraza može širiti - konidije i askospore.

Osim na vinovoj lozi, vrste $P$. mortoniae, $P$. aleophilum i P. rubrigenum nađene su širom svijeta u brojnim drugim kultiviranim ili samoniklim 
D. Ivić i sur.: Phaeoacremonium vrste u vinovoj lozi sa simptomima eske i Petrijeve bolesti

drvenastim biljkama domaćinima (Sami i sur., 2014.; Mostert i sur., 2006.; Damm i sur., 2008.; Eskalen i sur., 2005.). Te vrste pokazale su se patogenima, primjerice, na jabuci, krušci i dunji (Sami i sur., 2014.), maslini (Carlucci i sur., 2015.), šljivi ili marelici (Damm i sur., 2008.), dok je njihova patogenost na drugim domaćinima uglavnom još neistražena. Pretpostavlja se da brojne drvenaste biljke na kojima su zabilježene Phaeoacremonium vrste također mogu biti izvor inokula za zarazu vinove loze.

Istraživanje je pokazalo da su Phaeoacremonium vrste povezane s eskom i Petrijevom bolesti vinove loze u Hrvatskoj slične kao u drugim zemljama svijeta (Bertsch i sur., 2013.; Surico, 2009.; Mostert i sur., 2006.). Uz tri vrste utvrđene u ovom istraživanju ( $P$. mortoniae, $P$. aleophilum i $P$. rubrigenum), među potencijalnim uzročnicima eske i Petrijeve bolesti u Hrvatskoj su prije utvrđene i gljive Phaeomoniella chlamydospora (Cvjetković i Ivić, 2004.), Phaeoacremonium croatiense (Essakhi i sur., 2008.) te Fomitiporia mediterranea (Ivić i sur., 2015.). Nalaz peritecija T. fraxinopennsylvanica, T. minima i $T$. rubrigena na čokotima sa simptomima eske pokazuje da se te gljive na zaraženim biljkama mogu razmnožavati spolno i širiti askosporama.

\section{LITERATURA}

1. Aroca, A., Raposo, R. (2009.):Pathogenicity of Phaeoacremonium species on grapevines. Journal of Phytopathology 157: 413-419.

2. Bertsch, C., Ramírez-Suero, M., Magnin-Robert, M., Larignon, P., Chong, J., Abou-Mansour, E., Spagnolo, A., Clément, C., Fontaine, F. (2013.): Grapevine trunk diseases: complex and still poorly understood. Plant Pathology 62: 243-265.

3. Bruno, G., Sparapano, L., Graniti, A. (2007.): Effects of three esca-associated fungi on Vitis vinifera L.: IV. Diffusion through the xylem of metabolites produced by two tracheiphilous fungi in the woody tissue of grapevine leads to esca-like symptoms on leaves and berries. Physiological and Molecular Plant Pathology 71: 106-124.

4. Carlucci, A., Lops, F., Cibelli, F., Raimondo, M.L. (2015.): Phaeoacremonium species associated with olive wilt and decline in southern Italy. European Journal of Plant Pathology 141: 717-729.

5. Cvjetković, B., Ivić, D. (2004.): Esca - apoplektično venuće starih I mladih čokota vinove loze. Glasilo biljne zaštite 6: 343-349.

6. Cvjetković, B. (2010.): Mikoze i pseudomikoze voćaka i vinove loze. Zrinski, Čakovec. 
D. Ivić i sur.: Phaeoacremonium vrste u vinovoj lozi sa simptomima eske i Petrijeve bolesti

7. Damm, U., Mostert, L., Crous, P.W., Fourie, P.H. (2008.): Novel Phaeoacremonium species associated with necrotic wood of Prunus trees. Persoonia 20: 87-102.

8. Essakhi, S., Mugnai, L., Crous, P.W., Groenewald, J.Z., Surico, G. (2008.): Molecular and phenotypic characterisation of novel Phaeoacremonium species isolated from esca diseased grapevines. Persoonia 21: 119-134.

9. Eskalen, A., Rooney-Latham, S., Gubler, W.D. (2005.): Occurrence of Togninia fraxinopennsylvanica on esca-diseased grapevines (Vitis vinifera) and declining ash trees (Fraxinus latifolia) in California. Plant Disease 89: 528.

10. Gramaje, D., Alaniz, S., Pérez-Sierra, A., Abad-Campos, P., García-Jiménez, J., Armengol, J. (2008.): First report of Phaeoacremonium scolyti causing Petri disease in Spain. Plant Disease 92: 836.

11. Gramaje, D., Mostert, L., Groenewald, J.Z., Crous, P.W. (2015.): Phaeoacremonium: From esca disease to phaeohyphomycosis. Fungal Biology 119: 759-783.

12. Gubler, W.D., Thind, T.S., Feliciano, A.J., Eskalen, A. (2004.): Pathogenicity of Phaeoacremonium aleophilum and Phaeomoniella chlamydospora on grape berries in California. Phytopathologia Mediterranea 43: 70-74.

13. Hofstetter, V., Buyck, B., Croll, D., Viret, O., Couloux, A., Gindro, K. (2012.): What if esca of grapevine were not a fungal disease? Fungal Diversity 54: 51-67.

14. Ivić, D., Sever, Z., Miličević, T. (2015.): An overview of grapevine esca in Croatia. IOBC-WPRS Conference of the Working group on "Integrated protection and production in viticulture", 20.-23. listopad 2015., Beč, Austrija.

15. Mostert, L., Groenewald, J.Z., Summerbell, R.C., Gams, W., Crous, P.W. (2006.): Taxonomy and pathology of Togninia (Diaporthales) and its Phaeoacremonium anamorphs. Studies in Mycology 54: 1-113.

16. Mugnai, L., Graniti, A., Surico, G. (1999.): Esca (black measels) and brown woodstreaking: Two old and elusive diseases of grapevine. Plant Disease 83: 404-418.

17. Rooney-Latham, S., Eskalen, S., Gubler, W.D. (2005.): Occurrence of Togninia minima perithecia in esca-affected vineyards in California. Plant Disease 89: 867871.

18. Sami, S., Mohammadi, H., Heydarnejad, J. (2014.): Phaeoacremonium species associated with necrotic wood of pome fruits in Iran. Journal of Plant Pathology 96: 487-495.

19. Sparapano, L., Bruno, G., Graniti, A. (2001.): Three-year observation of grapevines cross-inoculated with esca-associated fungi. Phytopathologia Mediterranea 40: S376-S386. 
D. Ivić i sur.: Phaeoacremonium vrste u vinovoj lozi sa simptomima eske i Petrijeve bolesti

20. Surico, G., Mugnai, L., Marchi, G. (2006.): Older and more recent observations on esca: a critical overview. Phytopathologia Mediterranea 45: S68-S86.

21. Surico, G. (2009.): Towards a redefinition of the diseases within the esca complex of grapevine. Phytopathologia Mediterranea 48: 5-10.

22. Tamura, K., Peterson, D., Peterson, N., Stecher, G., Nei, M., Kumar, S. (2011.): MEGA5: Molecular evolutionary genetics analysis using maximum likelihood, evolutionary distance, and maximum parsimony methods. Molecular Biology and Evolution 28: 2731-2739.

23. White, T.J., Bruns, T., Lee, S., Taylor, J.W. (1990.): Amplification and direct sequencing of fungal ribosomal RNA genes for phylogenetics. U: Innis MA, Gelfand DH, Sninsky JJ, White TJ (ur.) PCR protocols: A guide to methods and applications. New York, Academic Press Inc., pp. 315-322.

Adrese autora - Author's addresses:

dr. sc. Dario Ivić

e-mail: dario.ivic@hcphs.hr,

dr. sc. Zdravka Sever,

Petra Pilipović, mag. ing. agr.,

Hrvatski centar za poljoprivredu, hranu i selo, Zavod za zaštitu bilja

Gorice 68b, 10000 Zagreb

Ana Marija Čajkulić, dipl. ing.

Savjetodavna služba

Ivana Gorana Kovačića 13

33000 Virovitica

prof. dr. sc. Bogdan Cvjetković

Sveučilište u Zagrebu, Agronomski fakultet, Zavod za poljoprivrednu zoologiju

Svetošimunska cesta 25

10000 Zagreb
Primljeno - Received:

03.02.2017. 